\title{
BIOPROSPECÇÃO DE SUBSTÂNCIAS ANTI-FÚNGICAS PRODUZIDAS POR Actinomycetes ISOLADOS DA REGIÃO AMAZÔNICA.
}

Bioprospection of antifungal substances produced by Actinomycetes isolated from Amazon region

\section{João V. B. Souza ${ }^{1,2} *$; Regina Y. Moriya ${ }^{2,3}$; Érica S. Souza ${ }^{3}$}

${ }^{1}$ Laboratório de Micobacteriologia - Coordenação de Ciências da Saúde - Instituto Nacional de Pesquisas da Amazônia, Av. André Araújo, N² 2936, Bairro Aleixo, CEP 69060-001, ManausAmazonas;

${ }^{2}$ Laboratório de Micologia - Fundação de Medicina Tropical do Amazonas;

${ }^{3}$ Laboratório de Química - Centro Universitário Luterano de Manaus

Recebido em 24/06/2009 - Aceito em 08/09/2009

* Autor para correspondência e-mail: joaovicentebragasouza@yahoo.com.br

RESUMO: O objetivo geral deste trabalho foi investigar o potencial da bioprospecção de substâncias anti-fúngicas produzidas por Actinomycetes isolados da Região Amazônica. Especificamente, foi realizado o isolamento, seleção qualitativa e quantitativa de isolados produtores de anti-fúngicos, cromatografia de camada delgada e bioautografia das substâncias anti-fúngicas. Foram isoladas 41 linhagens, estas foram submetidas ao teste qualitativo quanto à produção de antifúngicos, 26, 4 e 29 foram os números de isolados que produziram substâncias antifúngicas contra Candida albicans, Candida glabrata e Cryptococcus neoformans, respectivamente. Os produtos de bioprocesso de 10 isolados foram selecionados e submetidos à determinação da concentração inibitória mínima (CIM) frente às linhagens patogênicas, sendo encontrados valores entre $0,9-22,4 \mu \mathrm{g} / \mathrm{mL}$. A bioautografia da fração etanólica dos isolados ACT2 e ACT46 apresentou atividade antifúngica frente a C. albicans e os valores de Rf foram diferentes dos observados para Anfotericina B.

PALAVRAS-CHAVE: Actinomycetes, produção de antifúngicos, bioautografia

ABSTRACT: The aim of this work was carried out a screening of Actinomycetes strains isolated from Amazonian soil for antifungal production. Strain isolation, qualitative and quantitative screening, thin layer chromatography and bioautography were carried out. 41 isolated were submitted for the qualitative screening for antifungal production and 26, 4 and 29 were the numbers of strains that 
Souza, J. V. B. et al./Revista Eletrônica de Farmácia Vol 6(3), 94-102, 2009.

produced inhibition to Candida albicans, Candida glabrata and Cryptococcus neoformans, respectively. The bioprocess products from 10 strains were submitted to the determination of minimal inhibitory concentration (MIC) of the pathogenic strains. The MIC values were between 0.9$22.4 \mu \mathrm{g} / \mathrm{mL}$. The bioautography from the ethanol soluble products produced by ACT2 and ACT 46 strains presented antifungal activity against $C$. albicans and with Rf values different from Anfotericin B.

KEYWORDS: Actinomycetes, antifungal production, bioautography 


\section{INTRODUÇÃO}

Durante as últimas duas décadas, a freqüência de infecções fúngicas sistêmicas tem aumentado. Isto pode ser atribuído ao número de pacientes que sofrem imunocomprometimento causado pela infecção pelo HIV, pelo tratamento com quimioterápicos e por transplantes, ou ainda, aqueles que passaram por procedimentos invasivos e fazem uso de anexos vasculares e/ou antimicrobianos de largo espectro (BOUDEMAGH et al.,2005 ). Novos patógenos e o surgimento de linhagens resistentes a anti-fúngicos também são preocupações contemporâneas (WIART et al.,2004; BOUDEMAGH et al.,2005).

Os Actinomycetes são uma das principais fontes de metabólitos secundários com atividade anti-celular (VERNEKAR et al.,2001, VODA et al.,2003, UZUKI et al.,2005; KITOUNI et al.,2005). Os Streptomyces spp constituem $50 \%$ do total da população de Actinomycetes do solo e $75 \%$ dos antibióticos utilizados na atualidade são produzidos por este gênero (NIKODINOVICA, 2003). Trabalhos de seleção de Actinomycetes com o objetivo de encontrar novas substâncias antimicrobianas continuam a ser realizados em grande número (BOUDEMAGH et al.,2005).

Poucas pesquisas investigaram novos produtos a partir de Actinomycetes isolados de regiões do planeta como China, Austrália e Marrocos (QUIROGA et al.,2001; OUHDOUCHA et al.,2001), da mesma forma, não há grupos de pesquisa instalados na Amazônia Brasileira investigando o potencial anti-fúngico das substâncias produzidas por Actinomycetes.

O objetivo deste trabalho foi investigar o potencial da bioprospecção de substâncias antifúngicas produzidas por Actinomycetes isolados da região amazônica. Especificamente, foi realizado o isolamento, seleção qualitativa e quantitativa de isolados produtores de antifúngicos, cromatografia de camada delgada e bioautografia das substâncias anti-fúngicas.

\section{MATERIAL E MÉTODOS}

\section{Isolamento e seleção de Actinomycetes produtores de anti-fúngicos da região amazônica.}

Isolamento: Foi realizado como descrito por BOUDEMAGH et al. (2005). Amostras de terra do município de Presidente Figueiredo (Município do estado do Amazonas localizado a $110 \mathrm{Km}$ da capital Manaus-AM) foram submetidas a diluições sucessivas em água (LACAZ et al.,2001) e inoculadas em superfície de meio de cultura (Agar EPG -extrato de levedura $3 \mathrm{~g} / \mathrm{L}$, extrato de malte $3 \mathrm{~g} / \mathrm{L}$, peptona $5 \mathrm{~g} / \mathrm{L}$, glicose $10 \mathrm{~g} / \mathrm{L}$ e $40 \mathrm{mg} / \mathrm{L}$ de actidione) contido em placas de petri. As colônias que se desenvolveram (21 dias a $25{ }^{\circ} \mathrm{C}$ ) com morfologia semelhante à Actinomycetes foram purificadas e preservadas sob-óleo mineral a 20 ${ }^{\circ} \mathrm{C}$ (LACAZ et al.,2001).

Seleção qualitativa: Foi realizada como descrito por QUIROGA, (2001). Inicialmente os fungos foram submetidos a um bioprocesso (1 $\mathrm{mL}$ de inóculo contendo $10^{5}$ células $/ \mathrm{mL}$ dos isolados foi transferido para Erlenmeyer de 125 $\mathrm{mL}$ contendo $25 \mathrm{ml}$ de caldo EPG e em seguida foram incubados sob agitação de $100 \mathrm{rpm}$, temperatura de $28^{\circ} \mathrm{C}$ por 120 horas) com a finalidade de produzir as substâncias antifúngicas. Os metabólitos presentes no caldo resultante do bioprocesso foram aliquotados $(100 \mu \mathrm{L})$ em "cup plates" feitos em meio de cultura (ágar RPMI 1640 suplementado de 
tampão MOPS e glicose $5 \%$ previamente inoculado $\left(10^{5}\right.$ células $\left./ \mathrm{mL}\right)$, em profundidade, com linhagens patogênicas (Cryptococcus neoformans FMT05, Candida albicans FMT132/06 e Candida glabrata FMT 130/06). As placas de petri foram incubadas (24 horas a temperatura de $28^{\circ} \mathrm{C}$ ) e, em seguida, foram determinados os tamanhos dos halos produzidos.

Seleção quantitativa (determinação do CIM): A seleção quantitativa foi feita como descrito pela CLSI-M21-A2 (2002). Dez produtos de bioprocessos selecionados a partir do experimento de seleção qualitativa foram submetidos à determinação da sua CIM. Concentrações entre 0,1-1000 $\mu \mathrm{g} / \mathrm{mL}$ destes produtos (secos sob pressão reduzida a $40{ }^{\circ} \mathrm{C}$ ) foram avaliadas frente a culturas líquidas (meio RPMI 1640, adicionado de tampão MOPS e glicose $5 \%$ ) contendo os fungos patogênicos (Cryptococcus neoformans FMT05 e Candida albicans FMT132/06). Anfotericina B foi 0 antimicrobiano utilizado como referência.

\section{Cromatografia de camada delgada e} bioautografia das substâncias antifúngicas.

Extrato alcoólico: Foi obtido como descrito por QUIROGA, (2001). Um grama de produto de bioprocesso seco (baixa pressão $40{ }^{\circ} \mathrm{C}$ ) foi misturado com $10 \mathrm{~mL}$ de etanol (96 \%) sob agitação orbital (50 rpm). O material insolúvel foi separado (filtração em papel Whatman no 5) e os componentes solúveis foram secos (baixa pressão $40{ }^{\circ} \mathrm{C}$ ).

Cromatografia de camada delgada: Foi realizada como descrito por SCHMOURLO et al, (2005). As amostras (1 mg) foram aplicadas em papel cromatográfico (G60 F250, $8 \mathrm{~cm} \times 8$ $\mathrm{cm}$ ), foram desenvolvidas (n-butanol/ácido acético/ água $8: 1: 1$ ) e em seguida reveladas com sulfato sérico e ultravioleta (254 e 366 $\mathrm{nm})$.

Bioautografia: Foi realizada como descrito por SCHMOURLO et al, (2005). Cromatogramas, feitos como descrito anteriormente, foram cobertos com uma camada de $4 \mathrm{~mm}$ de meio de cultura (ágar RPMI 1640 suplementado de tampão MOPS e glicose $5 \%$ ) previamente inoculado $\left(10^{5} / \mathrm{mL}\right)$ com a linhagem Candida albicans FMT132/06, este microrganismo foi selecionado por permitir uma discussão mais completa com trabalhos previamente realizados. As placas foram incubadas ( $48 \mathrm{~h}$ a $37{ }^{\circ} \mathrm{C}$ ) e reveladas (Cloreto de metiltiazoltetrazólico-5 $\mathrm{mg} / \mathrm{mL}$ ) para a observação das áreas de inibição.

\section{RESULTADOS E DISCUSSÃO}

Isolamento e seleção de Actinomycetes produtores de anti-fúngicos da região amazônica.

Neste trabalho, foram isoladas 41 linhagens de 4 amostras de solo superficial, contendo material vegetal em decomposição. As linhagens foram identificadas como Actinomycetes devido a sua macro e micromorfologia. A literatura descreve que a maioria dos isolados de solo de Actinomycetes são do gênero Streptomyces (RISK et al.,2007), nossos achados micromorfológicos nos fazem acreditar que a maior parte dos nossos isolados pertencem a este gênero.

$\mathrm{O}$ isolamento de Actinomycetes tem sido uma abordagem freqüente devido à capacidade destes de produzir metabólitos de interesse industrial (BURRES et al.,1995; HOLTZER et al.,2003). Actinomycetes são responsáveis pela 
Souza, J. V. B. et al./Revista Eletrônica de Farmácia Vol 6(3), 94-102, 2009.

produção de $70 \%$ dos antimicrobianos existentes incluindo eritromicina, tetraciclina, estreptomicina, clorafenicol, neomicina, nistatina, anfoterina $B$ e ciclohexamina (SIRVASTAVA \& SINGHAL, 2004) e novas substâncias continuam sendo descobertas (EGUCHI et al.,2004; TAECHOWISAN et al.,2005; KONIA et al.,2008; ARASU et al.,2009; ).

O meio de isolamento EPG foi modificado durante os experimentos devido ao isolamento de grande quantidade de colônias de fungos mitospóricos. A substituição de glicose por amido e a utilização de meio tamponado (tampão fosfato de potássio $0,01 \mathrm{M}, \mathrm{pH} 5,0$ ) favoreceu $\mathrm{o}$ isolamento dos organismos alvo. Alguns estudos têm demonstrado que os meios de cultivo são muito importantes no isolamento e produção de substâncias de interesse biotecnológico por Actinomycetes (RISK et al.,2007, LIANG et al.,2008; GAO, et al.,2009). Portanto, estudos como o realizado por GAO et al.,(2009), que utilizaram um planejamento multifatorial para a otimização da produção de avermectina B1 por Streptomyces avermitilis são fundamentais para caracterização de novos isolados.

A avaliação qualitativa teve como objetivo demonstrar quais microorganismos produziram antifúngicos. Esta abordagem é bem descrita na literatura e em vários trabalhos resultou no isolamento de linhagens promissoras (THAKUR et al.,2007). Neste trabalho, entre os 41 isolados, 26,4 e 29 isolados produziram substâncias com atividade antagônica para C. albicans, C. glabrata e C. neoformans, respectivamente (Tabela 1). THAKUR et al., 2007 realizaram uma seleção de Actinomycetes produtores de antifúngicos $\mathrm{e}$, entre 110 isolados, 47 produziram atividade antifúngica contra C. albicans, ou seja, fração "semelhante" a observada neste trabalho.

\section{C. albicans, C. glabrata e C. neoformans} foram sensíveis de forma diferente aos produtos de bioprocesso. As cepas de $C$. neoformans e $C$. albicans foram mais sensíveis que C. glabrata. Este resultado está de acordo com a literatura que apresenta $C$. glabrata como organismo intrinsecamente resistente aos antifúngicos existentes (FORREST, 2006).

Tabela 1. Caracterização das linhagens quanto à capacidade de produção de antifúngicos

\begin{tabular}{lcccccc}
\hline $\begin{array}{l}\text { Caracterização/ } \\
\text { Halo de inibição (mm) }\end{array}$ & $\begin{array}{l}\text { Candida } \\
\text { albicans }\end{array}$ & $\mathrm{n}(\%)$ & $\begin{array}{c}\text { Candida } \\
\text { glabrata }\end{array}$ & $\begin{array}{c}\mathrm{n} \\
(\%)\end{array}$ & $\begin{array}{c}\text { Cryptococcus } \\
\text { neoformans }\end{array}$ & $\mathrm{n}(\%)$ \\
\hline Não produtor/ 0 & 15 & 34,1 & 37 & 84,1 & 12 & 27,3 \\
Produtor/1- 15 & 5 & 11,4 & 4 & 9,1 & & \\
Forte produtor/ > 16 & 21 & 47,7 & & & 29 & 65,9 \\
\hline
\end{tabular}

A técnica da macrodiluição CLSI-M21-A2 foi utilizada para determinar a CIM de 10 produtos de bioprocessos frente às linhagens de C. albicans e $C$. neoformans (Tabela 2), sendo encontrados valores de CIM entre 0,9-22,4 $\mu \mathrm{g} / \mathrm{mL}$. Ressalta-se que os produtos de bioprocesso/fermentação não passaram por nenhum processo de purificação e que, portanto, possuem um grande potencial, uma vez que, apresentaram valores de CIM 
semelhante aos observados na literatura para

(FORREST, 2006).

antifúngicos como Fluconazol e Anfotericina B

Tabela 2. Concentração Inibitória Mínima dos produtos de bioprocesso dos isolados

\begin{tabular}{ccc}
\hline Extrato & $\begin{array}{c}\text { CIM para Candida } \\
\text { albicans } \mu \mathrm{g} / \mathrm{mL}\end{array}$ & $\begin{array}{c}\text { CIM para } \\
\text { Cryptococcus } \\
\text { neoformans } \mu \mathrm{g} / \mathrm{mL}\end{array}$ \\
\hline ACT1 & 1,97 & 1,97 \\
ACT 2 & 12 & 12 \\
ACT 18 & 2,24 & 22,4 \\
ACT 27 & 1,07 & 10,7 \\
ACT 28 & 1,22 & 1,22 \\
ACT 29 & 13,1 & 1,31 \\
ACT 32 & 1,31 & 1,31 \\
ACT 35 & 13,8 & 13 \\
ACT 46 & 11,3 & 1,13 \\
ACT 47 & 0,9 & 9,9 \\
\hline
\end{tabular}

Cromatografia de camada delgada e bioautografia das substâncias antifúngicas.

Os extratos etanólicos das linhagens ACT2 e ACT46 foram submetidos à cromatografia e, em seguida, a biautografia. Estas linhagens foram escolhidas por serem capazes de inibir o crescimento das três linhagens patogênicas estudadas. Zonas de inibição foram observadas nos Rfs de 0,61, 0,67 e 0,38 para Anfotericina B, produtos de ACT2 e produtos de ACT 46, respectivamente. Este resultado é importante, pois corrobora com a possibilidade de obtenção de novas substâncias.

A precipitação com etanol do meio fermentado permitiu a separação de polímeros, como polissacarídeos e proteínas, de micrometabólitos. Isto acontece, pois a solvatação e a interação entre as moléculas mudam fazendo com que os polímeros sejam encontrados como precipitados insolúveis e os micrometabólitos no sobrenadante. Utilizou-se a bioautografia, pois ela é uma metodologia interessante que combina a capacidade de separação da cromatografia de camada delgada com a descriminação de quais substâncias apresentam a bioatividade frente ao microrganismo testado (SCHMOURLO et al.,2005, THAKUR et al.,2007).

\section{CONCLUSÕES}

A técnica de isolamento foi útil para isolar Actinomycetes produtores de antifúngicos. A seleção qualitativa demonstrou que uma fração significativa dos microrganismos produziu substâncias com antagonismo para $C$. abicans e $C$. neoformans. As CIM determinadas, sem qualquer purificação, foram semelhantes às de antifúngicos comercializados. A biautografia indicou que os $\mathrm{Rf}$ dos antimicrobianos estudados são diferentes do Rf da Anfotericina B. 


\section{AGRADECIMENTOS}

Ao CNPq pelo auxílio financeiro (Edital Universal, 2006), a Fapeam pelo auxílio financeiro (Edital PPP, 2006) e a Telma Maria e Antonieta Silva pela assistência técnica. 


\section{REFERÊNCIAS BIBLIOGRÁFICAS}

ARASU M V, V.; DURAIPANDIYAN , AGASTIAN P.; IGNACIMUTHU S. In vitro antimicrobial activity of Streptomyces spp. ERI-3 isolated from Western Ghats rock soil (India). J. Mycologie Médicale, v. $19 ;$ p. 22-28, 2009.

BOUDEMAGH, A.; KITOUNI, M.; BOUGHACHICHE, F.; HAMDIKEN, H. ; OULMI, L. ; REGHIOUA, S.; ZERIZER, H.; COUBLE, A.; MOUNIEE, D. ; BOULAHROUF, A. ; BOIRON P. Isolation and molecular identification of actinomycete microflora, of some saharian soils of south east Algeria (Biskra,

EL-OUED AND OURGLA) study of antifungal activity of isolated strains. J. Mycologie Médicale, v. 15, p. 39-43, 2005.

BURRES, N.S.; PREMACHANDRAN, U.; HOSELTON, S.; CWIK, D.; HOCHLOWSKI, J.E.; YE, Q.; SUNGA, G.N.; MCALPINE, J.B. Simple aromatics identified with a NFAT-1acz transcription assay for the detection of immunosuppressants. J. Antibiotics, v. 48, p. 380-386, 1995.

EGUCHI, T.; YAMAMOTO, K; AND KAKINUMA, K. Structure revision of FD-819, a 16-membered macrolide antibiotic. J. Antibiotics, v, 57, p. 156-157, 2004.

FORREST G. Role of antifungal susceptibility testing in patient management. Current opinion in infectious diseases, v.19, p. 538-543, 2006.

GAO H.; LIU M.; LIU J.; DAI H.; ZHOU X.; LIU X; ZHUO Y,; ZHANG W, ZHANG L. Medium optimization for the production of avermectin B1a by Streptomyces avermitilis 14-12A using response surface methodology. Bioresource Technology. In press, 2009.

HOLTZER, A.; DIETER, A.; SCHMID, G.D.; BROWN, R.; GOODFELLOW, M.; BEIL, W.; JUNG, G.; FIEDLER, H. Lactonamycin $\mathrm{Z}$, an antibiotic and antitumor compound produced by Streptomyces sanglieri strain AK 623. J. Antibiotics, v. 56, p. 1058-1061, 2003.

KITOUNI M.;BOUDEMAGH A.;OULMI L.;REGHIOUA S. Isolation of actinomycetes producing bioactive substances from water, soil and tree bark samples of the north-east of Algeria. J. Mycologie Médicale, v.15, p. 45-51 2005.

KONYA A.; ZSUZSANNA SZABOLANG I,; INBARTA I,; SALA'T. Production of FK520by Streptomyces tubercidicus. Microbiological Research. v.163, p.624-632, 2008.

LACAZ; C.S.; PORTO, E.; MARTINS, J.E.C. Microbiologia médica: fungos, actinomicetos e algas de interesse médico. $8^{\mathrm{a}}$ ed ., São Paulo: Sarvier, 1991. 
Souza, J. V. B. et al./Revista Eletrônica de Farmácia Vol 6(3), 94-102, 2009.

LIANG, J,; XUA, Z,; LIU, T.; LIN, L,; PEILIN, C. P. Effects of cultivation conditions on the production of natamycin with Streptomyces gilvosporeus LK-196. Enzyme Microbial Technology . v. 42, p. $145-150,2008$.

NATIONAL COMMITTEE FOR CLINICAL LABORATORY STANDARDS (CLSI). Reference method for broth dilution antifungal susceptibility testing of yeasts. Approved standard M27-A2. National Committee for Clinical Laborator y Standards, Wayne, Pa. ,2002.

NIKODINOVICA, J.; BARROWA, K. D.; CHUCKB, J. High frequency transformation of the Amphotericin producing bacterium Streptomyces nodosus. J. Microbiological Methods. v. 55, p. 273$277,2003$.

OUHDOUCHA, Y.; BARAKATE, M,; FINANCE, C. Actinomycetes of Moroccan habitats: Isolation and screening for antifungal activities. Eur. J. Soil Biol. v. 37, p. 69-74. 2001.

QUIROGA, E. N.; SAMPIETRO, A. R.; VATTUONE, M. A. Screening antifungal activities of selected medicinal plants. J. Ethnopharmacology. v. 74, p. 89-96, 2001.

RIZK, M., ABDEL-RAHMAN, T, ;METWALLY, H. Antibiotics production by Streptomyces lavendulae under different cultural conditions. J. Food, Agriculture \& Environment.v. 5, p. 412-415 , 2007 a.

SCHMOURLO, G.; MENDONÇA-FILHO, R. R.;ALVIANO, C. S.; COSTA, S.S. Screening of antifungal agents using ethanol precipitation and bioautography of medicinal and food plants. $J$. Ethnopharmacology . v.96,p. 563-568, 2005.

SIRVASTAVA, S.; SINGHAL, V. Advances in general microbiology. Fundamental of Microbiology. v.3, p. 176-177, 2004.

TAECHOWISAN, T.; LU, C.; SHEN, Y.; LUMYONG, S. Secondary metabolites from endophytic Streptomyces aureofaciens CMUAc130 and their antifungal activity. Microbiology. v. 151, p. 16911695, 2005.

THAKUR, D.; YADAV, A.; GOGOI, B. K.; BORA, T.C. Isolation and screening of Streptomyces in soil of protected forest areas from the states of Assam and Tripura, India, for antimicrobial metabolites. J. Mycologie Médicale. v.17, p. 242-249, 2007.

USUKI, Y.; MITOMO, K.; ADACHI, N.; PING, X.; FUJITA, K.; SAKANAKA, O; IINUMA, K;IIOA, H.; TANIGUCHIB, M. Semi-synthesis and biological evaluation of analogues of UK-2A a novel antifungal 
antibiotic from Streptomyces sp. 517-02. Bioorganic \& Medicinal Chemistry Letters. v. 15, p. 2011$2014,2005$.

VERnEKAR, J.V.; TANKSALE, A. M.; GHATGE, M. S.; DESHPANDE; V. V. Novel Bifunctional Alkaline Protease Inhibitor: Protease Inhibitory Activity as the Biochemical Basis of Antifungal Activity. Biochemical and Biophysical Research Communications . v. 285, p. 1018-1024, 2001.

VODA, K.;BOH, B.; VRTA-CNIK, M.;POHLEVEN, F. Effect of the antifungal activity of oxygenated aromatic essential oil compounds on the white-rot Trametes versicolor and the brown-rot Coniophora puteana. International Biodeterioration \& Biodegradation. v. 51, p. 51 - 59 , 2003.

WIART, C. ; MOGANA, S. ; KHALIFAH, S. ; MAHAN, M. ; ISMAIL, S. ; BUCKLE, M.; NARAYANA, A. K.; SULAIMAN, M. Antimicrobial screening of plants used for traditional medicine in the state of Perak Peninsular Malaysia. Fitoterapia. v. 75, p. 68-73, 2004. 